\title{
DEVELOPMENT OF IDENTIFICATION METHOD FOR A DRAFT VERSION OF PHARMACOPOEIA MONOGRAPH "FRANGULA BARK"
}

\author{
(C) Evdokimova O. V., Obukhova V. V., Kuzminova L.V.
}

JSC "Krasnogorskleksredstva", Krasnogorsk, Moscow region, Russia

Russian State Pharmacopoeia $\mathrm{XI}^{\text {th }}$ edition suggests to use just test tube reactions for identification of Frangula bark. But according to the modern requirements for normative documentation on herbal medicinal products, it is more reasonable to use TLC method. The purpose of our study was to develop and validate a new TLC method for Frangula bark identification. The study object was Frangula bark; TLC was chosen as an analytical method for identification of phenolic compounds profile in the samples. In order to harmonize with leading Pharmacopoeias mobile phase ethyl acetate - 96\% ethanol - water (100:17:13) was used (European Pharmacopoeia 7.104/2011:0025). The chromatographic analysis was carried out in the plates TLC silica gel 60 (aluminium sheets, Merck, Germany). Solutions of barbaloin and quercetin were used as reference solutions. $5 \%$ alcoholic potassium hydroxide solution was used for detection. The following zones were present $365 \mathrm{~nm}$ in the chromatograms obtained with the reference solutions: the zone with brown-yellow, greenyellow or yellow color $\left(R_{f}\right.$ approx. $0.3-0.4$ that was accepted as $R_{s}=1.0$, due to barbaloin) and the zone with light blue color ( $R_{s}$ approx. 0.6-0.7, due to quercetin). The following zones of phenolic compounds were present $365 \mathrm{~nm}$ in the chromatograms obtained with the test solution: 2 zones with orange-red or orange color
( $R_{s}$ (by barbaloin) approx. 0.5-0.7 and 1.7-1.9); others zones could be present with the exception of the zone with yellow or red-orange color $\left(R_{s}\right.$ approx. 1.0 , due to reduced forms of anthracene derivatives). Method validation included evaluation of chromatographic system specificity and suitability. The method specificity was evaluated by coincidence of the different batches chromatographic profiles by the main zones and by compliance of abovementioned profiles with the test solution chromatogram description. The method validation was performed on 4 industrial batches. Chromatographic profiles of the different batches have coincided and been compliant with the test solution chromatogram description. The resolution between zones of quercetin $\left(R_{s}\right.$ approx. 0.6-0.7) and barbaloin ( $R_{s}$ approx. 1.0) in the chromatogram obtained with the reference solution has been chosen as a chromatographic system suitability index. The resolution value between the chosen zones must not be less than 1.5. The resolution values that had been calculated by the chromatograms obtained from different batches satisfied the method requirements. The suggested method can be used for identification of Frangula bark in routine analyses. This method has been included into the draft version of Pharmacopoeia monograph "Frangula bark" for XIIth edition of the Russian State Pharmacopoeia.

\section{CHIMERIC ESTERS DERIVED FROM PLANT PHENOLIC ACIDS AND BORNEOL MODULATE HUMAN ENDOTHELIAL CELL ACTIVITIES IN VITRO - A NOVEL STRATEGY IN DRUG DISCOVERY}

\section{(c) Zhao Xin-feng ${ }^{1,2}$, Nordahl Lillian², Ahmed Uzma ${ }^{2}$, Ang Jackie ${ }^{2}$, Cho Chin-wen Chantal $^{2}$, Rahman Taufiq ${ }^{2}$, Zheng Xiao-hui ${ }^{1}$, Fan Tai-Ping ${ }^{2}$}

${ }^{1}$ College of Life Sciences, Northwest University, Xi'an 710069, China,

${ }^{2}$ Angiogenesis \& Chinese Medicine Laboratory, Department of Pharmacology, University of Cambridge, Cambridge CB2 1PD, United Kingdom, e-mail: tpf1000@cam.ac.uk

Angiogenesis is a major pathological component of diseases such as cancer and coronary heart disease. Over the last decade, researchers have discovered proand anti-angiogenic compounds from herbs used in traditional Chinese medicine. For example, we revealed that ginsenosides Rgi and Rb! from American, Chinese, Korean, and Sanqi ginseng produce opposing activities on the vascular system (1), through activation of glucocorticoid (2) and oestrogen (3) receptors and distinct signalling pathways. We also showed the natural compound $\mathrm{n}$-butylidene phthalide derived from the volatile oil of Radix Angelica sinensis to inhibit angiogenesis in vitro and in vivo (4). More evidence-based research and chemical optimisation of these compounds could further 